Special Issue of the 6th International Congress \& Exhibition (APMAS2016), Maslak, Istanbul, Turkey, June 1-3, 2016

\title{
Thermal Decomposition Kinetics of Algerian Tamazarte Kaolin by Differential Thermal Analysis (DTA)
}

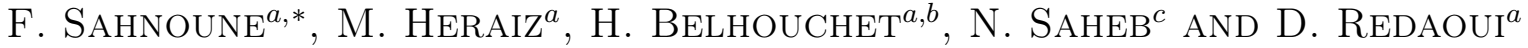 \\ ${ }^{a}$ Physics and Chemistry of Materials Lab, Department of Physics, University of M'sila, 28000, M'sila, Algeria \\ ${ }^{b}$ Laboratoire des Matériaux non Métalliques, I. O. M. P, Université Ferhat Abbas Sétif 1, 19000, Sétif, Algérie \\ ${ }^{c}$ Departments of Mechanical Engineering, King Fahd University of Petroleum and Minerals, \\ Dahran, 31261, Saudi Arabia
}

\begin{abstract}
In the present study, the kinetics of meta-kaolinite $\left(\mathrm{Al}_{2} \mathrm{O}_{3} \cdot 2 \mathrm{SiO}_{2}\right)$ formation from Algerian Tamazarte kaolin was investigated by using differential thermal analysis. The differential thermal analysis and the thermogravimetric experiments were carried out on samples between room temperature and $1400^{\circ} \mathrm{C}$, at heating rates from 10 to $40^{\circ} \mathrm{C} \mathrm{min}{ }^{-1}$. X-ray diffraction was used to identify the phases present in the samples. The activation energies measured by differential thermal analysis from isothermal and non-isothermal treatments using Johnson-MehlAvrami methods with Ligero approximation and using Kissinger-Akahira-Sunose methods were around 145 and $159 \mathrm{~kJ} / \mathrm{mol}$, respectively. The Avrami parameter $n$ which indicates the growth morphology parameters were found to be almost equal to 1.60, using non-isothermal treatments, and equal to 1.47 using isothermal treatments. The numerical factor which depends on the dimensionality of crystal growth was 1.60 obtained using Matusita et al. equation. The frequency factor calculated using the isothermal treatment is equal to $1.173 \times 10^{7} \mathrm{~s}^{-1}$. Analysis of the results have shown that bulk nucleation was dominant during kaolinite transformation, followed by three-dimensional growth of meta-kaolinite with polyhedron-like morphology, controlled by diffusion from a constant number of nuclei.
\end{abstract}

DOI: 10.12693/APhysPolA.131.382

PACS/topics: 82.30.Lp, 81.05.Je, 81.05.Mh, 81.70.Pg

\section{Introduction}

Kaolin is usually used in a various number of applications, for example in the ceramic industry: conventional ceramics, structural and refractory ceramics, microelectronic packaging, high-temperature protective coatings, microwave dielectrics and infrared-transmitting materials. Further, other than ceramics applications, kaolin is also utilized as an industrial filler agent for paper, rubber, plastics, cosmetics, paints, etc. $[1,2]$. In addition, kaolin can be utilized for management of waste, preparation of geopolymers, membranes, geopolymer-based composites [3-5], intercalates and zeolites. Metakaolin is produced by calcination of kaolin rock. It has found utilizations in food processing industry, ceramics and shale oil processing [2]. All these applications are based the thermal transformation of kaolinite and main mineral phase of kaolin rock.

Thus, the course of mullite development from kaolin has been proven by a number of methods and techniques, such as thermogravimetric analysis (TGA), differential thermal analysis (DTA), differential scanning calorimetry (DSC) and dilatometry. In published literature [6-10] the mechanism and kinetics of thermal decomposition of kaolinite and of general clay mineral are considered with a wide interest. A broad-spectrum of methods, including molecular spectroscopy, electron microscopy and

*corresponding author; e-mail: sahnounefoudil@yahoo.com thermal analysis techniques have been used to investigate this process [7-10]. The aim of the present paper is to study two corresponding processes during thermal decomposition of kaolin, such as dehydroxylation of kaolinite and the mechanism of dehydroxylation. Finally the important kinetic parameters (overall activation energy and pre-exponential factor) will be determined on the basis of DTA experiments.

\section{Materials and experimental procedure}

Raw kaolin (from Tamazarte, Jijel, Algeria) was used in this investigation. Its chemical composition, determined by X-ray fluorescence (XRF) is shown in Table I. The raw kaolin was milled in planetary ball mill with alumina grinding media for $4 \mathrm{~h}$ and after that, milled by attrition for $2 \mathrm{~h}$ using $\mathrm{ZrO}_{2}$ balls (diameter of $1.25 \mathrm{~mm}$ ) at a speed of $700 \mathrm{rev} \mathrm{min}^{-1}$. The slurry was dried at $120^{\circ} \mathrm{C}$ for $24 \mathrm{~h}$, powdered then sieved through a $63 \mu \mathrm{m}$ mesh.

The thermal analysis (DTA-TG) was carried out on a Setaram LABevo TG-DSC $1600^{\circ} \mathrm{C}$ equipment, operating under argon atmosphere. The samples were heated from room temperature up to $1400^{\circ} \mathrm{C}$ at heating rates of 10 to $40^{\circ} \mathrm{C} \mathrm{min}^{-1}$. The DTA scans were conducted in flowing air, using alumina crucibles. The phases and their transformations were characterised using diffractometer system XPERT-PRO, with scan step of $0.0167^{\circ}$ $\left(\mathrm{Cu} \mathrm{K} \mathrm{K}_{\alpha}\right.$ radiation and a $\mathrm{Ni}$ filter), operated at $40 \mathrm{kV}$ and $40 \mathrm{~mA}$. The kinetics and the mechanism of kaolinite transformation have been studied by two dissimilar methods, such as non-isothermal or isothermal. According to the information obtained about the thermal activities of Kaolin, each technique gives excellent results. 
TABLE I

Chemical composition of the raw kaolin [wt.\%].

\begin{tabular}{c|c|c|c|c|c|c|c|c}
\hline \hline $\mathrm{Al}_{2} \mathrm{O}_{3}$ & $\mathrm{SiO}_{2}$ & $\mathrm{Na}_{2} \mathrm{O}$ & $\mathrm{P}_{2} \mathrm{O}_{5}$ & $\mathrm{SO}_{3}$ & $\mathrm{~K}_{2} \mathrm{O}$ & $\mathrm{MgO}$ & $\mathrm{CaO}$ & $\mathrm{Fe}_{2} \mathrm{O}_{3}$ \\
\hline 33.00 & 61.73 & 0.14 & 0.03 & 0.03 & 2.96 & 0.44 & 0.44 & 0.80
\end{tabular}

\section{Results and discussion}

Figure 1 shows DTA/TG and DTG curves of kaolin powder heated from room temperature to $1400^{\circ} \mathrm{C}$ at a heating rate of $40^{\circ} \mathrm{C} \mathrm{min}^{-1}$. Two step-like weight losses are observed on the TG curve. The first step of weight loss $(\Delta m=2 \%)$ is due to the evaporation of adsorbed water and the formation of kaolinite from kaolin. This transformation corresponds to the endothermic peak at $139.1^{\circ} \mathrm{C}$, as seen on the DTA curve, otherwise at $123.6^{\circ} \mathrm{C}$ (first peak) on the DTG curve. The second step of weight loss $(\Delta m=10 \%)$ is due to the dehydroxylation of kaolinite and the formation of metakaolinite. It corresponds to the endothermic peak at $591.1^{\circ} \mathrm{C}$, seen on the DTA curve, and corresponds to the second peak on the DTG curve at $585.9^{\circ} \mathrm{C}$. Two other exothermic peaks are observed on the DTA curve. The first one at $999.1^{\circ} \mathrm{C}$ corresponds to the formation of $\mathrm{Al}-\mathrm{Si}$ spinel phase and the second peak at $1201.6^{\circ} \mathrm{C}$ corresponds to the formation of primary mullite and to transformation of amorphous $\mathrm{SiO}_{2}$ state into a crystalline phase, cristobalite.

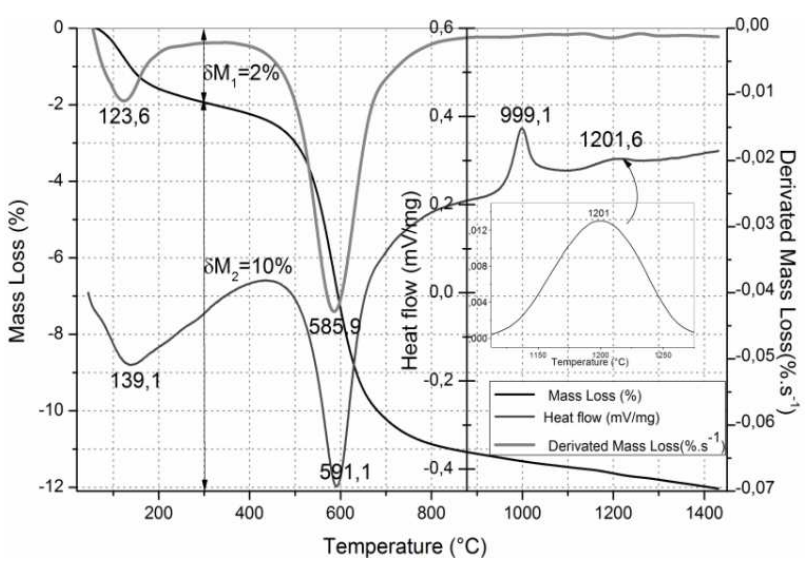

Fig. 1. DTA/TG, DTG curves of Tamazaret kaolin powder heated at $40{ }^{\circ} \mathrm{C} \mathrm{min}{ }^{-1}$.

Figure 2 shows XRD patterns of raw kaolin powder (Tamazarte) treated at different temperatures for $1 \mathrm{~h}$. From room temperature only reflections of aluminum silicate hydroxide $\left(\mathrm{Al}_{2} \mathrm{Si}_{2} \mathrm{O}_{5}(\mathrm{OH})_{4}\right.$ kaolinite $)$ and of silicon oxide $\left(\mathrm{SiO}_{2}\right.$ quartz) were present. At $700^{\circ} \mathrm{C}$ there is a complete transformation of kaolinite to meta-kaolinite and no transformation in silicon oxide. At $1200^{\circ} \mathrm{C}$ the transformation of spinel phase to primary mullite is finished and cristobalite starts to form through the transformation of the quartz. All transformations of kaolin in DTA/DTG results are confirmed by the XRD phase analysis, as shown in Fig. 2.

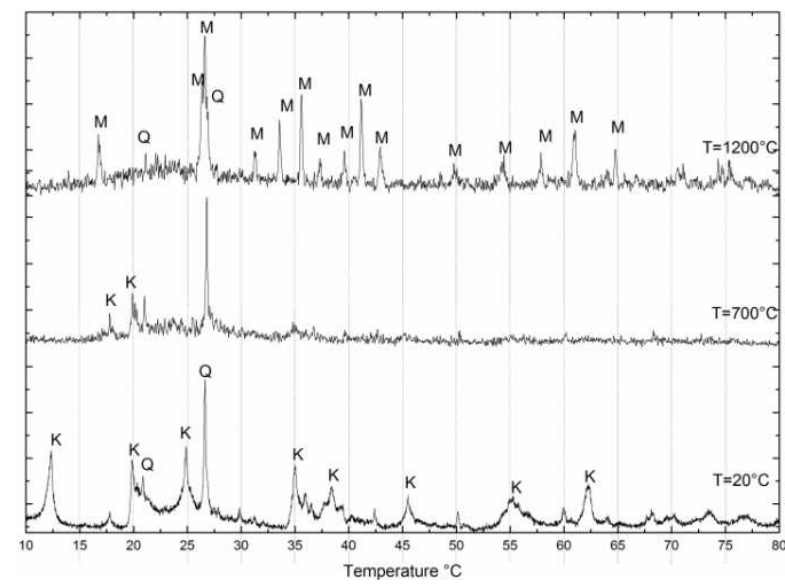

Fig. 2. X-ray diffraction of raw kaolin treated at different temperatures.

Figure 3 shows the variation of the crystallized fraction of metakaolinite (dehydroxylated kaolinite) which was calculated from DTA data [11] and the rate of crystallized fraction, as functions of time, for different heating rates $\left(10,15,20,25,30,35\right.$ and $\left.40^{\circ} \mathrm{C} / \mathrm{min}\right)$. The increase of heating rate changes the rate of the variation of the crystallized fraction from 0.003 to $0.011 \mathrm{~s}^{-1}$ and the time of the crystallization decreases from 650 to $175 \mathrm{~s}$.

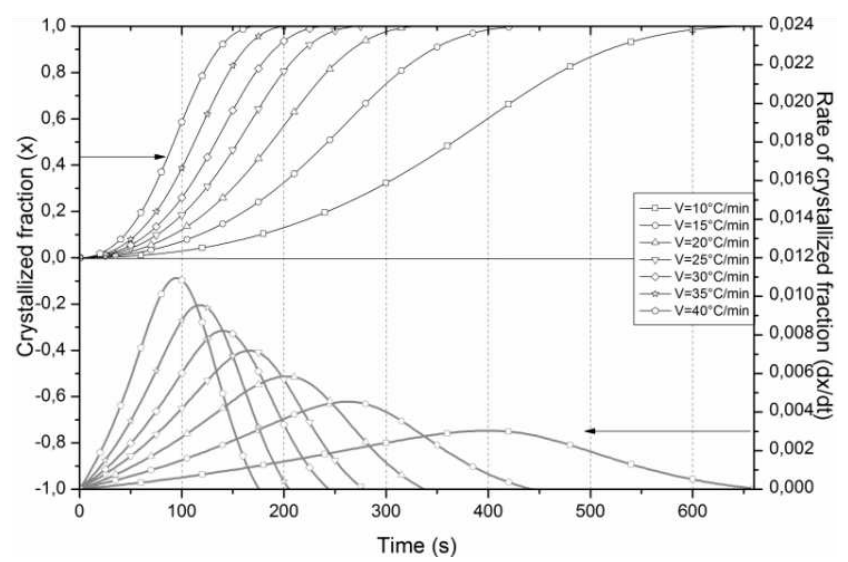

Fig. 3. Crystallized fraction and rate of increase of crystallized fraction for different heating rates.

A mathematical method based on non-isothermal techniques was proposed by Ligero and co-workers [11]. If the same value of crystallized fraction $x$ in every experiment at different heating rates is selected, the result will be a linear curve, as shown in Fig. 4. The activation energy $E_{\mathrm{A}}$ can be calculated from the slope of the function $\ln (\mathrm{d} x / \mathrm{d} t)=f(1 / T)[12,13]$. The values of $E_{\mathrm{A}}$ for different crystallized fractions were calculated by the average of the slopes of the lines, which are listed in Table II. The coefficient of determination $R^{2}$ is greater than 0.99 for different $x$ values. The average of activation energy of dehydroxylated kaolinite is $145.5 \mathrm{~kJ} \mathrm{~mol}^{-1}$. 


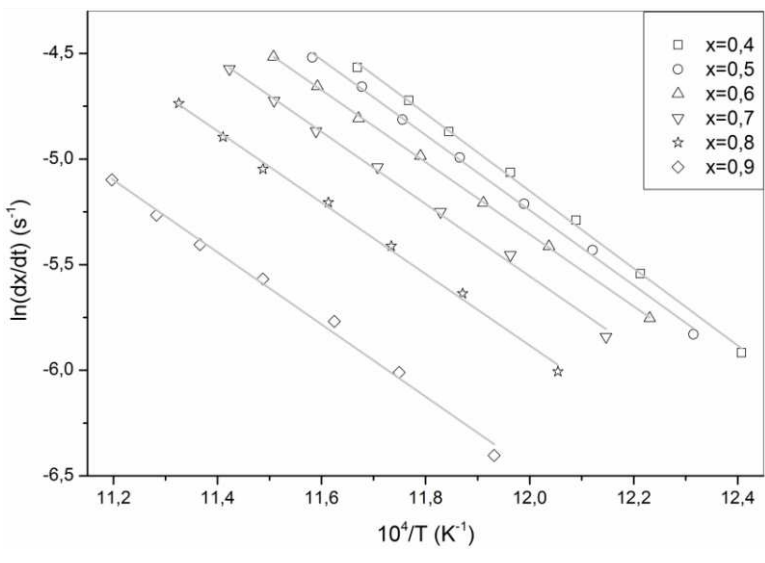

Fig. 4. Plot of $\ln (\mathrm{d} x / \mathrm{d} t)$ versus $1 / T$ at same value of crystallized fraction $x$, at different heating rates, obtained from DTA experiment.

TABLE II

Values of activation energy $E_{\mathrm{A}}$ and the coefficient of determination for different values of crystallized fraction.

\begin{tabular}{c|c|c|c|c|c|c|c|c|c}
\hline \hline $\begin{array}{c}\text { Cryst. } \\
\text { frac. } x\end{array}$ & 0.1 & 0.2 & 0.3 & 0.4 & 0.5 & 0.6 & 0.7 & 0.8 & 0.9 \\
\hline $\begin{array}{c}R^{2} \\
E_{\mathrm{A}} \\
{[\mathrm{kJ} / \mathrm{mol}]}\end{array}$ & 0.993 & 0.994 & 0.998 & 0.997 & 0.998 & 0.999 & 0.997 & 0.997 & 0.993 \\
& 147 & 149 & 152 & 147 & 142 & 142 & 141 & 142
\end{tabular}

The Avrami parameter, $n$, was determined by the selection of many pairs of $x_{1}$ and $x_{2}$ that satisfied the condition $\ln \left[k_{0} f\left(x_{1}\right)\right]=\ln \left[k_{0} f\left(x_{2}\right)\right]$ and by using Eq. $1[11]$.

$$
n=\frac{\ln \left[\ln \left(1-x_{2}\right) / \ln \left(1-x_{1}\right)\right]}{\ln \left[\left(1-x_{2}\right) \ln \left(1-x_{2}\right) /\left(1-x_{1}\right) \ln \left(1-x_{1}\right)\right]} .
$$

The average values of Avrami parameter $n$ for each heating rate are listed in Table III. Its values are equal to 1.47. The frequency factor, $k_{0}$, for the different heating rates can also be calculated by the following Eq. 2, the average of $k_{0}$ is equal to $1.173 \times 10^{7} \mathrm{~s}^{-1}$.

$$
\begin{aligned}
& \ln \left(k_{0} f(x)\right)=\ln \left(k_{0}\right)+\ln (n) \\
& \quad+\frac{n-1}{n}[\ln (-\ln (1-x))]+\ln (1-x) .
\end{aligned}
$$

From the ratio of times for two fixed degrees of transformation, the morphology of the crystal growth can be obtained $[13,14]$. A suitable representative index is the ratio of times for $75 \%$ and $25 \%$ transformation. In such way we find $2.20 \leq t_{0.75} / t_{0.25} \leq 4.82$ for one dimensional growth (needles), $1.69 \leq t_{0.75} / t_{0.25} \leq 2.20$ for two-dimensional growth (plates) and $1.48 \leq t_{0.75} / t_{0.25} \leq$ 1.69 for 3D growth (polyhedron).The average values of $t_{0.75} / t_{0.25}$ for each heating rate are listed in Table III. For all heating rates the average value is equal to 1.68. This suggests a three dimensional growth of metakaolinite crystals [13].
TABLE III

Values of the Avrami parameter, $t_{0.75} / t_{0.25}$ values and the frequency factor for different heating rates.

\begin{tabular}{c|c|c|c}
\hline \hline $\begin{array}{c}\text { Heating } \\
\text { rate }\left[{ }^{\circ} \mathrm{C} \mathrm{min}^{-1}\right]\end{array}$ & $\begin{array}{c}\text { Avrami } \\
\text { param. } n\end{array}$ & $\begin{array}{c}t_{0.75} / t_{0.25} \\
\text { value }\end{array}$ & $\begin{array}{c}\text { Frequency } \\
\text { factor } k_{0}\end{array}$ \\
\hline 10 & 1.427 & 1.669 & $1.118 \times 10^{7}$ \\
15 & 1.492 & 1.689 & $1.187 \times 10^{7}$ \\
20 & 1.476 & 1.692 & $1.273 \times 10^{7}$ \\
25 & 1.493 & 1.675 & $1.228 \times 10^{7}$ \\
30 & 1.479 & 1.666 & $1.129 \times 10^{7}$ \\
35 & 1.477 & 1.688 & $1.154 \times 10^{7}$ \\
40 & 1.455 & 1.731 & $1.124 \times 10^{7}$
\end{tabular}

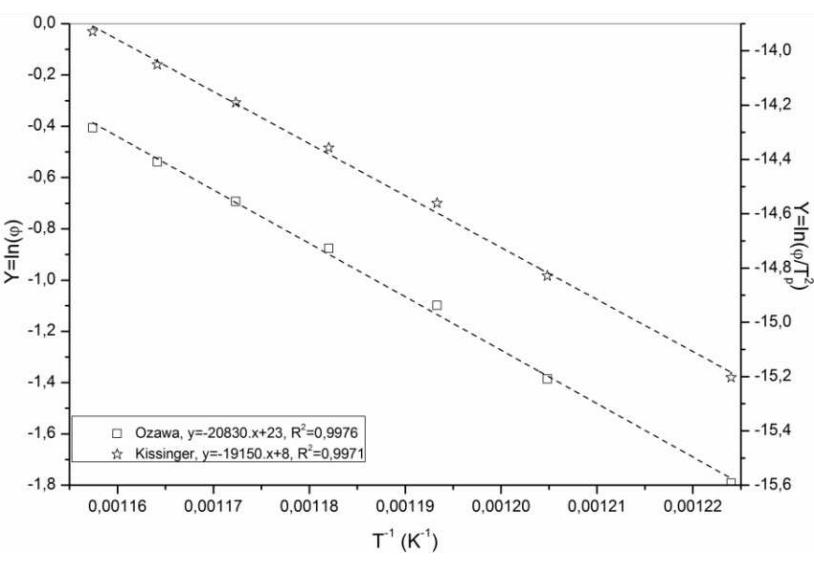

Fig. 5. Plots of $Y$ versus $1 / T_{p}$ of dehydroxylation of kaolinite at different heating rates.

TABLE IV

The values of $E_{\mathrm{A}}$ and $R^{2}$ of dehydroxylated kaolinite by using Ozawa and Kissinger methods.

\begin{tabular}{c|c|c}
\hline \hline Method & Ozawa & Kissinger \\
\hline Activation energy $E_{\mathrm{A}}[\mathrm{kJ} / \mathrm{mol}]$ & 165 & 159 \\
$R^{2}$ & 0.9976 & 0.9971
\end{tabular}

Figure 5 represents the plots of $Y$ versus $1 / T_{p}$ according to Kissinger-Akahira-Sunose and Ozawa-Flynn-Wall methods. The values of the activation energies of dehydroxylated kaolinite, calculated from the slope of the function $Y_{i}=f\left(1 / T_{p}\right)$ are listed in Table IV. The average of activation energy is $162 \mathrm{~kJ} \mathrm{~mol}^{-1}$. It is in good agreement with that of $145.5 \mathrm{~kJ} \mathrm{~mol}^{-1}$ estimated using isothermal DTA treatment. Table V represents the values of the Avrami parameter $n$, which indicate the crystallisation mode for different heating rates, determined using Eq. 3.

$$
n=\frac{2.5 T_{p}^{2} R}{\Delta T_{p} E_{A}} .
$$

The average Avrami parameter is equal to 1.60. This value is close to 1.5, which suggests, that the crystallization process of meta-kaolinite should be controlled by diffusion growth [14]. The dimensionality of crystal growth $m$, calculated from the slope of the function $\ln \left(v^{n} / T_{p}^{2}\right)=$ 
$f\left(1 / T_{p}\right)$, according to Matusita (Eq. 4) is found to be equal to 1.60 for the dehydroxylated kaolinite.

$$
\ln \left[\frac{v^{n}}{T_{p}^{2}}\right]=C_{3}-\frac{m E_{\mathrm{A}}}{R T_{p}} .
$$

Both of the growth morphology parameters $n$ and $m$ are close to 1.5, these results also indicate that the bulk nucleation is the dominant mechanism in metakaolinite crystallisation and the crystal growth is controlled by diffusion from a constant number of nuclei.

TABLE V

Values of the Avrami parameter $n$ for different heating rates, obtained from DTA experiments.

\begin{tabular}{c|c|c|c|c|c|c|c}
\hline \hline heating rates $\left[{ }^{\circ} \mathrm{C} / \mathrm{min}\right]$ & 10 & 15 & 20 & 25 & 30 & 35 & 40 \\
\hline$\Delta T$ & 53.774 & 54.126 & 56.547 & 57.312 & 59.9881 & 61.288 & 61.470 \\
$T_{p}$ peak & 543.989 & 556.928 & 565.273 & 572.793 & 580.101 & 586.199 & 591.346 \\
$n$ & 1.611 & 1.652 & 1.613 & 1.620 & 1.5752 & 1.563 & 1.578
\end{tabular}

\section{Conclusions}

The kinetics and mechanism of dehydroxylation of Algerian Tamazarte kaolinite was investigated using DTA techniques. From the obtained results authors have concluded the following:

- The activation energy, measured by DTA from isothermal and non-isothermal treatments was around 145.5 and $162 \mathrm{~kJ} / \mathrm{mol}$, respectively.

- The Avrami parameters $n$ of growth morphology were found to be around 1.60 and 1.47 using nonisothermal and isothermal treatments, respectively.

- The numerical factor $m$, which depends on the dimensionality of crystal growth, is found to be 1.60 , using Matusita equation.

- The frequency factor calculated by the isothermal treatment is equal to $1.173 \times 10^{7} \mathrm{~s}^{-1}$.

- The bulk nucleation was dominant in kaolinite transformation, followed by three-dimensional growth of metakaolinite with polyhedron-like morphology (controlled by diffusion from a constant number of nuclei).

\section{References}

[1] H. De Aza, X. Turrillas, M.A. Rodriguez, T. Duran, P. Pena, J. Eur. Ceram. Soc. 34, 1409 (2014).

[2] F. Franco, L.A. Pérez-Maqueda, J.L. Pérez-Rodriguez, J. Colloid Interface Sci. 274, 107 (2004).
[3] A. Harabi, B. Boudaira, F. Bouzerara, L. Foughali, F. Zenikheri, A. Guechi, B. Ghouil, S. Condom, Acta Phys. Pol. A 127, 1164 (2015).

[4] D. Kirsever, N. Karakus, N. Toplan, H.O. Toplan, Acta Phys. Pol. A 127, 1042 (2015).

[5] L. Domka, A. Malicka, N. Stachowiak, Acta Phys. Pol. A 114, 413 (2008).

[6] F. Sahnoune, N. Saheb, B. Khamel, Z. Takkouk, J. Therm. Anal. Calorim. 107, 1067 (2012).

[7] K. Heide, M. Földvari, Thermochim. Acta 446, 106 (2006).

[8] J. Temuujin, K. Okada, K.J.D. MacKenzie, T.S. Jadambaa, J. Eur. Ceram. Soc. 19, 105 (1999).

[9] K. Traoré, F. Gridi-Bennadji, P. Blanchart, Thermochim. Acta 451, 99 (2006).

[10] N. Saikia, P. Sengupta, P.K. Gogoi, P.Ch. Borthakur, Appl. Clay Sci. 22, 93 (2002).

[11] R.A. Ligero, J. Vazques, P. Villares, R. JimenezGaray, J. Mater. Sci. 26, 211 (1991).

[12] M. Romero, J. Martın-Marquez, J.Ma. Rincon, J. Eur. Ceram. Soc. 26, 1647 (2006).

[13] K. Matusita, K. Miura, T. Komatsu, Thermochim. Acta 88, 283 (1985).

[14] P. Ptáček, D. Kubátová, J. Havlica, J. Brandštetr, F. Šoukal, T. Opravil, Powder Technol. 204, 222 (2010). 